\title{
Analysis of solar heating system for an aquaponics food production system
}

\author{
Kevin R. Anderson ${ }^{1}$, Maryam Shafahi ${ }^{1}$, Arthur Artounian ${ }^{1}$, Adam Chrisman ${ }^{2}$ \\ ${ }^{1}$ Mechanical Engineering Department, Solar Thermal Alternative Renewable Energy Lab, College Engineering, California State Polytechnic \\ University, Pomona, CA, USA \\ ${ }^{2}$ SUNEARTH Inc., Fontana, CA, USA
}

Email address:

kranderson1@csupomona.edu (K. R. Anderson), maryam.shafahi@email.ucr.edu (M. Shafahi), artounianarthur@gmail.com (A.Artounian), AChrisman@SunEarthInc.com (A. Chrisman)

\section{To cite this article:}

Kevin R. Anderson, Maryam Shafahi, Arthur Artounian, Adam Chrisman. Analysis of Solar Heating System for an Aquaponics Food Production System. International Journal of Sustainable and Green Energy. Vol. 4, No. 1, 2015, pp. 1-11. doi: 10.11648/j.ijrse.20150401.11

\begin{abstract}
Aquaponics is a sustainable farming technology that combines aquaculture and hydroponics, growing fish and plants together in a symbiotic environment. Aquaponics sets an excellent example for an efficient multidisciplinary solution to the real world problems such as drought, polluted environment and food contamination. In this paper we present an aquaponics system heated by solar thermal energy in order to maintain the fish living environment at $21^{\circ} \mathrm{C}$. The paper presents an $f$-chart based analysis demonstrating the feasibility of the system. The results show for a collector area of $22 \mathrm{~m}^{2}$ that an annual solar fraction of $94 \%$ is needed to support an 833 liter aquaponics system.
\end{abstract}

Keywords: Solar Thermal Energy, Aquaponics, Sustainable, Renewable, f-Chart

\section{Introduction}

The State of California in the USA is facing its most severe drought emergency in decades while more than $70 \%$ of its water consumption is attributed to agriculture. This state needs more low-demand and water-efficient agriculture systems to overcome its long-term water crisis. Aquaponics, an increasingly popular farming system, produces fish and crops with $10 \%$ of the amount of water used in traditional farming [1]. Additionally, crop production represents the largest source of groundwater nitrate in the majority of agricultural lands in California which has been raising public health concerns [2]. Utilizing aquaponics requires $90 \%$ less water and little fertilizers for the plant growth. It provides faster growth rate, crop maturity and yields, and better quality of the crops. Moreover, aquaponics is able to grow crops in places where ordinary horticulture and aquaculture is impossible due to poor or contaminated soil or water. Another beneficial factor is minimizing the growing area [35]. Aquaponics sets an excellent example for an efficient multidisciplinary solution to the real world problems such as drought, polluted environment and food contamination. It is a rescue plan involving specialists from agriculture, science, engineering, and business.

The aquaponics system described herein grows tilapia and gold fish with a combination of different crops such as romaine lettuce, celery, Swiss chard, ruby chard and lettuce The optimum water temperature for producing tilapia is between 70 to $75^{\circ} \mathrm{F}$ [4]. In order to maintain the appropriate temperature for the fish, the fish tanks of the aquaponics system must be equipped with efficient heat exchangers. Additionally, the water quality should be monitored continuously to ensure the level of $\mathrm{pH}$, temperature, Ammonia, Nitrite and Nitrite fulfills the aquaponics rather limited ecosystem's demands. The long-term goal of this research is to establish a local model which will predict the performance of the systems in terms of plant yield and fish growth accounting for the influence of weather, fish and plant type, as well as water and energy consumption. The two existing systems are outdoors utilizing gravel and rafting bed for plant growing. This research is sustainable since we can find a market for our truly organic crops and fish. The current test set-up is shown in Figure 1.The ultimate goal of this research is to build a solar thermal heating system for the aquaponics system. This paper presents the results of a solar thermal design analysis of such a system. 


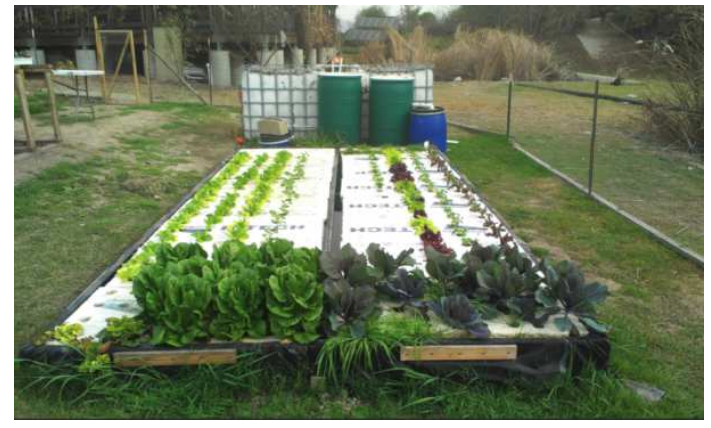

Figure 1. Aquaponics sustainable food production facility.

\section{Materials and Methods}

The present paper is a continuation of the work presented in $[7,8]$. The solar thermal heating system aquaponics test set-up at Cal Poly Pomona is shown schematically in Figure 2.

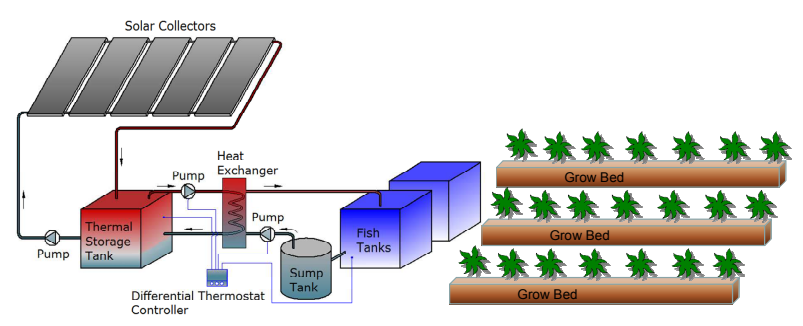

Figure 2. Solar thermal heating system schematic.

The solar thermal system to be integrated into the aquaponics system is used to offset the energy cost of powering auxiliary heaters during cold weather. This will allow aquaponics system to be used in regions where the weather fluctuates vastly over 24 hours. Figure 2 shows the fish living environment and aquaponics grow beds. The waste matter harvested from the fish tanks is diverted to the grow beds in order to fertilize the crops. Figure 3 shows the details of how the fish tanks are integrated to the grow beds using the aerator, bio-filter and clarifier. The fish are housed in the fish tanks, which is held at a desired temperature of 70 ${ }^{\circ} \mathrm{F}$ by the solar thermal energy system so that the fish can survive cold evening temperature variations.

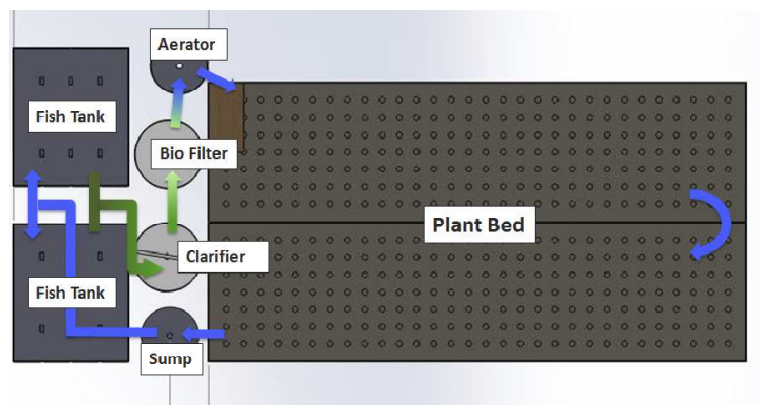

Figure 3. Aquaponics sustainable food production facility.

The system shown in Figure 2 consists of the following hardware:

- Solar Collectors: an array of 5 SUNEARTH Oasis-PP solar thermal collectors with a gross area of 236 square feet tilted at 34 degrees from the horizontal

- Thermal Storage Tank: an insulated 220 gallon storage tank with an integrated drain-back unit into the closedloop system

- Heat Exchanger: a counter-flow heat exchanger between the storage tank and the fish tanks isolate the solar thermal heating loop from the fish supply water

- Data logger: a four-channel thermocouple data logger is used to record the inlets and outlets of the heat exchanger

- Pump: the solar collector loop flow rate is regulated by a timer, which functions only during daylight hours

- Differential Thermostatic Controller: the pumps directing the flow from the storage tank into the heat exchanger are activated by a multiple-relay differential thermostatic controller according to the following algorithm; if a $10^{\circ} \mathrm{F}$ delta between the thermal storage tank and fish tanks is detected or when the fish tank temperature drops below $68^{\circ} \mathrm{F}$

Figure 4 shows a typical temperature variation in the aquaponics fish tanks versus time.

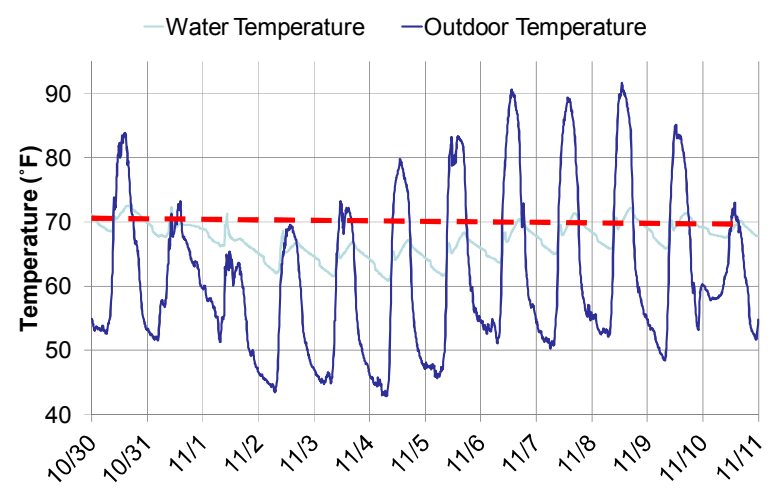

Figure 4. Temperature variations in fish tanks.

The data shown in Figure 4 was recorded over two weeks. This data is for the aquaponics system utilizing $100 \%$ auxiliary pool heaters to meet the load i.e. zero solar thermal corresponds to $600 \mathrm{~W}$ per month (or $7.2 \mathrm{~kW}$ annually) required by the pool heaters, which is taken from measurement on the current system configuration.

Clearly, using pool heaters is not a green/renewable/sustainable solution for large scale aquaponics infrastructures. Thus, herein a design a solar thermal heating system to offset the cost of auxiliary pool heaters is presented. In the remaining sections of this paper we discuss the proposed design and analysis of the solar thermal based heating system for the aquaponics fish tanks.

\section{Solar Thermal Analysis}

The $f$-chart analysis method of [8] was used to perform a feasibility on the solar thermal heating of the system shown in Figure 2. The $f$-chart method is a correlation of the results of many hundreds of thermal performance simulations of solar heating systems. The resulting simulations give $f$, the 
fraction of the monthly heating load (for space heating and hot water) supplied by solar energy as a function of two dimensionless parameters, $X$ (collector loss) and $Y$ (collector gain). $X$ is related to the ratio of collector losses to heating loads, and $Y$ is related to the ratio of absorbed solar radiation to the heating loads. The basic equations of the $f$-chart method per [9] are summarized below, beginning with the expressions for the collector loss, $X$ and the collector gain, $Y$

$$
\begin{aligned}
& X=F_{R} U_{c} \frac{F_{R}^{\prime}}{F_{R}}\left(T_{r e f}-\bar{T}_{a}\right) \Delta \tau \frac{A_{c}}{L} \\
& Y=F_{R}(\tau \alpha)_{n} \frac{F_{R}^{\prime}}{F_{R}} \frac{(\overline{\tau \alpha})}{(\tau \alpha)_{n}} \overline{H_{T}} N \frac{A_{c}}{L}
\end{aligned}
$$

The $f$-chart equations for the fraction $f$ of the monthly space and water heating loads supplied by solar energy for liquid based systems (such as that one considered herein) is given by

$$
f=1.029 Y-0.065 X-0.245 Y^{2}+0.0018 X^{2}+0.0215 Y^{3}
$$

Figure 5 shows a $f$-chart for liquid systems. As shown in Figure 5, solar thermal design engineers can utilize the $f$ chart by computing the $X, Y$ values and then determining the corresponding $f$ value.

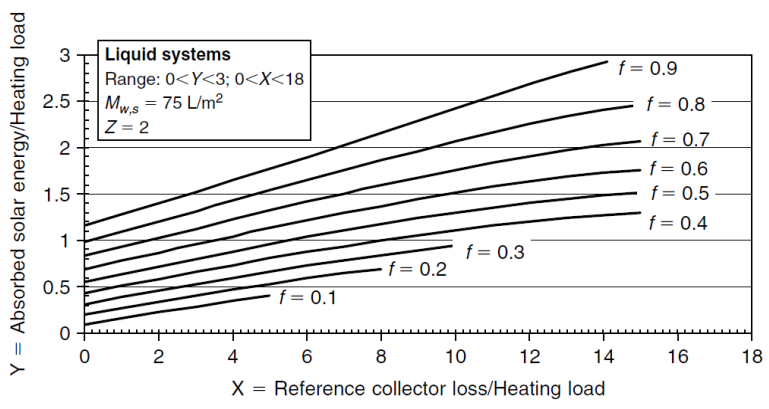

Figure 5. The f-chart for liquid based solar heating systems [10].

The fraction $F$ of the annual heating load supplied by solar energy is the sum of the monthly solar energy contributions divided by the annual load and is given as follows:

$$
F=\frac{\sum f L}{\sum L}
$$

where the following nomenclature is used in Eqns. (1) through Eqn. (4)

$$
\begin{aligned}
& A_{c}=\text { area of solar collector }\left(\mathrm{m}^{2} \text { or } \mathrm{ft}^{2}\right) \\
& f=\text { fraction of the monthly heating load carried by } \\
& \text { solar energy }(\%) \\
& F_{R}^{\prime}=\text { collector heat exchanger efficiency factor }(\%) \\
& F_{R}=\text { collector heat removal factor }(\%) \\
& F=\text { fraction of the annual heating load supplied by } \\
& \text { solar energy }(\%)
\end{aligned}
$$

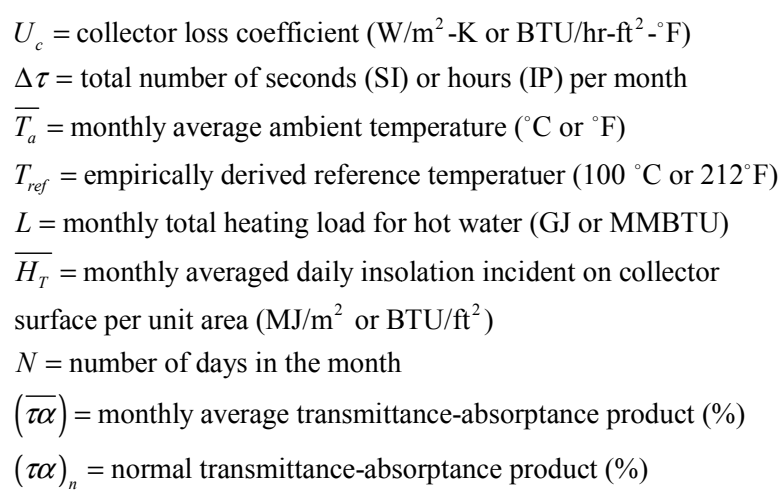

\section{Solar Thermal Results}

The solar thermal design simulation software tool PolySun [11] was used to generate the results presented herein. Figure 6 shows a layout of the system as analyzed in PolySun.

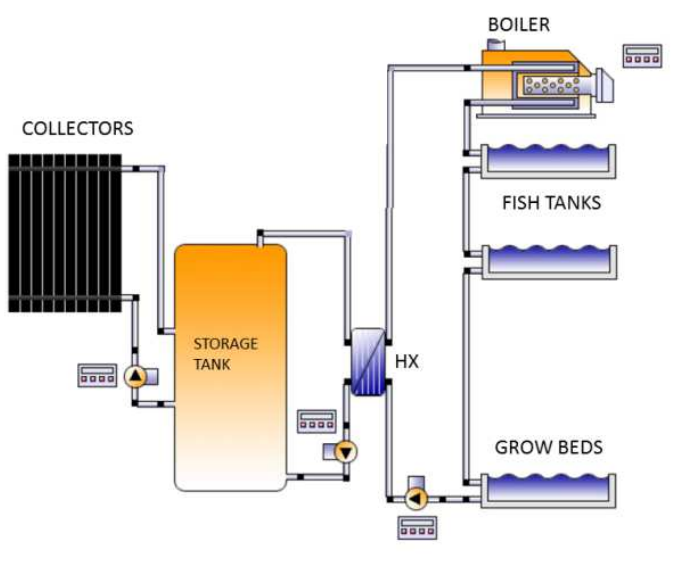

Figure 6. Schematic layout of solar heating system for the aquaponics food production system.

As shown in Figure 6, the system analyzed is composed of the following: collectors:

5 unglazed $48 \mathrm{ft}^{2}$ of area each, total collector area $=236.25$ $\mathrm{ft}^{2}$ at a tilt angle of $34^{\circ}$. There are two fish tanks 220 gal each, two commercial scale grow beds with a capacity of 250 plants, two filtration devices; clarifier/settling tanks, and a mineralizer /bio-filter. As shown in Figure 6, a boiler is used to interface the water in the fish tanks to the water in the heat exchanger. This provides the required isolation of the contaminated fish tank water from the storage tank water. The boiler is specified at $1.8 \mathrm{kBTU} / \mathrm{hr}$ with an efficiency of $35 \%$. The heat exchanger which interfaces the storage tank to the fish tanks is a shell/plate style rated at a thermal resistance of $\mathrm{R}=2 \times 10^{-4} \mathrm{~K} / \mathrm{W}$. The main pump in the solar thermal loop has a flow rate of $19 \mathrm{gpm}$ with a pressure drop of 28 psi and power consumption of $4997 \mathrm{kBTU}$. The pump in the fishtank is 16 gpm, 1.94 psi pressure drop and a power draw of $84 \mathrm{kBTU}$. Finally, the storage tank drainback system is rated at 150 gal.

Figure 7 shows the solar energy input to the system. Figure 7 plots solar energy into the system (kBTUs) vs. month of the 
year.

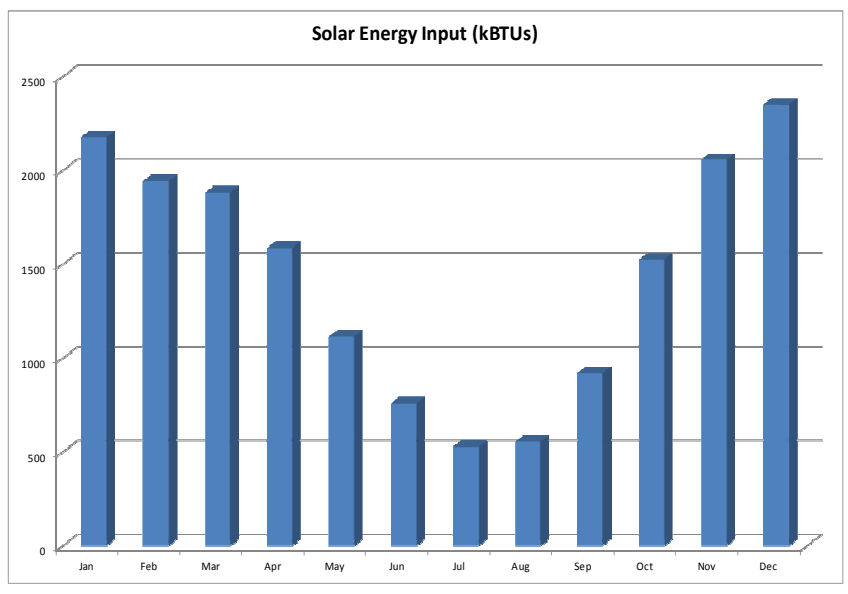

Figure 7. Solar energy input to the system (values in $k B T U s$ ).

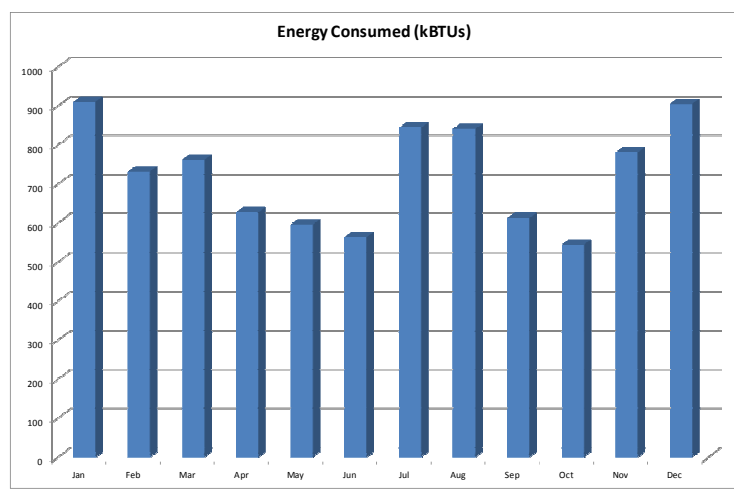

Figure 8. Energy consumed by the system (values in kBTUs).

Figure 8 plots the energy consumed by the system (kBTUs) vs. month of the year. Table 1 shows the f-chart calculations for this solar heating system for an aquaponics food production application of thermal energy harnessing and storage.

Table 1. $f$-chart Analysis summary.

\begin{tabular}{llllllll}
\hline Month & Avg. $\boldsymbol{H}_{\boldsymbol{T}}\left(\mathbf{M J} / \mathbf{m}^{\mathbf{2}}\right)$ & $\mathbf{A v g} . \boldsymbol{T}_{\mathbf{a}}\left({ }^{\circ} \mathbf{C}\right)$ & $\boldsymbol{L}(\mathbf{G J})$ & $\boldsymbol{P}_{\boldsymbol{L}}$ & $\boldsymbol{P}_{\boldsymbol{s}}$ & Solar fraction $\boldsymbol{f}$ & $\boldsymbol{f} \boldsymbol{L}(\mathbf{G J})$ \\
\hline Jan & 10.1 & 13 & 1.72 & 28.9 & 2.3 & 0.95 & 1.63 \\
Feb & 13.1 & 13 & 1.89 & 23.9 & 2.4 & 0.84 & 1.59 \\
Mar & 17.3 & 16 & 2.28 & 21.3 & 2.9 & 0.88 & 2.01 \\
Apr & 21.8 & 17 & 2.55 & 18.1 & 3.2 & 0.90 & 2.30 \\
May & 23.1 & 19 & 2.35 & 19.7 & 3.8 & 0.97 & 2.28 \\
Jun & 23.7 & 22 & 2.10 & 20.7 & 4.2 & 1.00 & 2.10 \\
Jul & 25.7 & 24 & 1.80 & 24.2 & 5.5 & 1.00 & 1.80 \\
Aug & 23.5 & 25 & 1.60 & 26.8 & 5.7 & 1.00 & 1.60 \\
Sep & 19.0 & 25 & 1.65 & 25.4 & 4.3 & 1.00 & 1.65 \\
Oct & 15.0 & 20 & 1.75 & 26.4 & 3.3 & 1.00 & 1.75 \\
Nov & 11.4 & 16 & 1.80 & 26.1 & 2.4 & 0.88 & 1.58 \\
Dec & 9.3 & 12 & 1.78 & 28.4 & 2.0 & 0.86 & 21.53 \\
Total & & & 23.27 & & & & \\
\hline
\end{tabular}

From Table 1 it is found that the fraction $F$ of the annual heating load supplied by solar energy is

$$
F=\sum f L / \sum L=21.82 / 23.27=94 \%
$$

Figure 9 shows the fraction of solar energy to the system $f$ per month

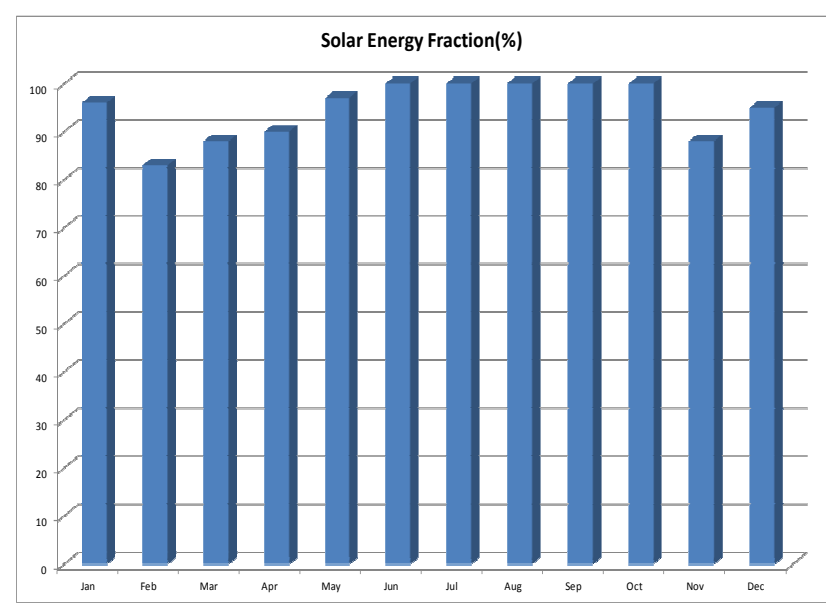

Figure 9. Solar energy fraction carried by the system, $f(\%)$.
The heat exchanger penalty factor analysis was carried out using the following expression per [10]

$$
F_{H X}=\frac{F_{R}^{\prime}}{F_{R}}=\left[1+\left(\frac{F_{R} U_{c}}{\left(\dot{m} c_{p}\right)_{c}}\right)\left(\frac{\left(\dot{m} c_{p}\right)_{c}}{\left(\dot{m} c_{p}\right)_{\min } \varepsilon}\right)-1\right]^{-1}
$$

where

$F_{H X}=$ heat exchanger penalty factor

$\left(\dot{m} c_{p}\right)_{c}=$ thermal capacitance of the collector

$\left(\dot{m} c_{p}\right)_{\min }=$ minimum thermal capacitance

$\varepsilon=$ heat exchanger effectiveness.

Application of Eqn. (5) to the current system using a Stainless-steel plate/shell heat exchanger rated at 790 provided the data of Table 2 . 
Table 2. Heat exchanger penalty factor analysis.

\begin{tabular}{lllll}
\hline $\boldsymbol{\varepsilon}$ & Penalty $\mathbf{F}_{\mathbf{h x}}$ & $\mathbf{N T U}$ & $\mathbf{A}_{\mathbf{H x}}\left(\mathbf{m}^{2}\right)$ & Energy Collection $\mathbf{Q}_{\mathbf{u}}(\mathbf{G J} / \mathbf{y r})$ \\
\hline 0.21 & 0.963 & 0.25 & 0.12 & 0.10 \\
0.30 & 0.974 & 0.40 & 0.19 & 0.15 \\
0.40 & 0.980 & 0.58 & 0.28 & 0.23 \\
0.50 & 0.984 & 0.82 & 0.40 & 0.32 \\
0.60 & 0.987 & 1.13 & 0.55 & 0.44 \\
0.70 & 0.989 & 1.55 & 0.76 & 0.61 \\
0.80 & 0.990 & 2.22 & 1.08 & 0.87 \\
0.90 & 0.991 & 3.42 & 1.67 & 1.35 \\
0.99 & 0.992 & -8.83 & 3.83 & 3.09 \\
1.00 & 0.992 & -- & -- \\
\hline
\end{tabular}

where $N T U=$ number of transfer units for the heat exchanger, $A_{H X}=$ heat exchanger area $\left(\mathrm{m}^{2}\right)$, and $Q_{u}=$ the useful energy collected (GJ/yr). The results of $\varepsilon$-NTU of Table 2 are seen to be in agreement with standard references in Heat Exchanger design [12]. The average temperature of the fish tanks is shown in Figure 10.

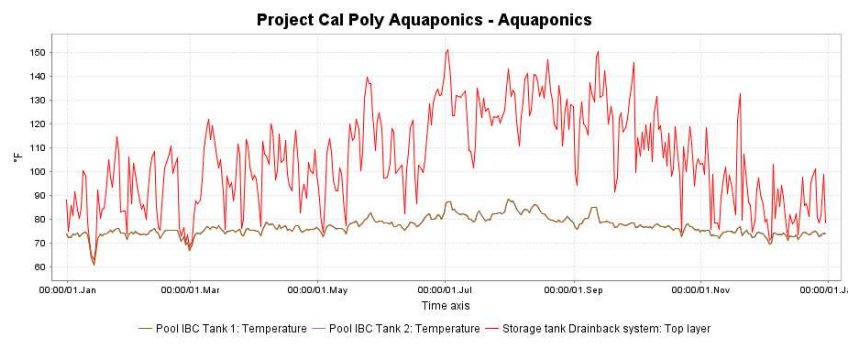

Figure 10. Aquaponics fish tank temperature transient.

Figure 10 illustrates that the solar thermal system as designed herein will hold the fish tanks in the aquaponics system at an average of $70^{\circ} \mathrm{F}$ as desired.

\section{Conclusions}

This paper has presented the analysis of a solar thermal heating system proposed for an aquaponics sustainable food production system. The f-chart analysis method based on [9] suggests that $94 \%$ of annual energy is carried by the solar thermal collectors / heat exchanger / storage tank system. This option of using solar thermal is a viable green energy solution as opposed to the current baseline design on using pool heaters to heat the aquaponics fish tanks, which requires on average $7.2 \mathrm{~kW}$ annual to maintain the fish tanks at the proper temperature. This paper has also presented a heat exchanger design simulation showing that an effectiveness of $75 \%$ provides $\mathrm{NTU}=2$. This value is in agreement with standard results for heat exchanger design a found in [12]. Future work involves the procurement and installation of the solar thermal heating system analyzed herein. From whence on-site data for thermal performance can be gathered and disseminated.

\section{References}

[1] Goodman, Community and Economic Development, Master's thesis, Massachusetts Institute of Technology, 2011

[2] Kristin N. Dzurella, Josué Medellín-Azuara, Vivian B. Jensen, Aaron M. King, Nicole De La Mora, Anna Fryjoff-Hung, Todd S. Rosenstock, Thomas Harter, Richard Howitt, Allan D. Hollander, Jeannie Darby, Katrina Jessoe, Jay Lund, G. Stuart Pettygrove, Nitrogen Source Reduction to Protect Groundwater Quality, Center for Watershed Sciences, University of California, Davis, July 2012

[3] Rakocy, J., Masser, M., Losordo, T., Recirculating Aquaculture Tank Production Systems: Aquaponics- Integrating Fish and Plant Culture, SRAC Publication No. 454, 2006

[4] Tyson, R. V., Reconciling $\mathrm{pH}$ for Ammonia Biofilteration in a Cucumber/Tilapia Aquaponics System Using a Perlite Medium, PhD thesis, University of Florida, 2007

[5] Blidariu F., Grozea A., Increasing the Economical Efficiency and Sustainability of Indoor Fish Farming by Means of Aquaponics - Review, Animal Science and Biotechnologies, 2011, $44(2)$

[6] "Application of Solar Power in Sustainable Food Production Systems" by Matt Shekels, Daniel Woolston, Dr. Maryam Shafahi, Dr. Kevin Anderson, Mechanical Engineering, California State Polytechnic University at Pomona poster presented at SOLAR 2014, San Francisco, CA, July 6-10, 2014

[7] "Application of Solar Power on Sustainable Food Production System" by Dr. Maryam Shafahi, Dr. Kevin R. Anderson, Jeff Moore, Darius Shu, Hadasa Reyes, Erik Mora, Roslina Hussin, Department of Mechanical Engineering, California Polytechnic State University, Pomona. Southern California Conferences for Undergraduate Research (SCCUR), Saturday, November 22, 2014.

[8] J.A. Duffie and W. A. Beckman, Solar Engineering of Thermal Processes, John Wiley and Sons, New York, NY, USA, $2^{\text {nd }}$ edition, 1991.

[9] Klein, S.A., 1976. A design procedure for solar heating systems. Ph.D. Thesis, Chemical Engineering, University of Wisconsin, Madison. 
[10] Kalogirou, S, 2009. Solar Energy Processes and Systems, $1^{\text {st }}$ Ed., Elsevier Publications, London, UK.

[11] PolySun Simulation software http://www.velasolaris.com/
[12] Heat Transfer, Incropera and Dewitt, $2^{\text {nd }}$ Ed. McGraw-Hill, 1991, NY, NY. 